\title{
The haemodynamic assessment of patients with pulmonary arterial hypertension
}

Stefano Ghio

\section{INTRODUCTION}

Right heart catheterization (RHC) has a crucial role in the management of patients with pulmonary hypertension (PH). Firstly, it is mandatory in subjects with the suspicion of $\mathrm{PH}$ to confirm the diagnosis. Secondly, it is strongly recommended in the follow-up of patients with confirmed pulmonary arterial hypertension (PAH) to evaluate drug efficacy and in case of clinical deterioration ${ }^{1}$.

In order to always perform a complete and correct RHC, clinicians carrying out the examination must be guided not only by technical recommendations, but also by the accurate knowledge of the different clinical issues which have to be addressed in these different situations (Table 1).

\section{BEST PRACTICE GUIDANCE}

RHC can be a challenging procedure in patients with $\mathrm{PH}$ and requires expertise, attention to detail, and meticulous collection of data².

Whenever possible, RHC should be performed in stable, non-acute clinical conditions. Although any systemic large vein may be used for venous access ${ }^{3,4}$, the femoral and internal jugular veins are most commonly used in clinical practice. The femoral access is easily compressible and complications (e.g., pseudoaneurysm, arteriovenous fistula, or retroperitoneal bleeding) are more likely when arterial and venous access are both obtained. The main disadvantage is the need for bed rest after the procedure.

The internal jugular vein allows easy access to the pulmonary artery. Complications are uncommon using an ultrasound-guided approach which gives the possibility to minimize the risks of the procedure, visualizing the location of the jugular vein (lateral or anterior or medial to the carotid artery) and the direction of the needle.

A wrong zero-level set is among the most common mistakes and a major confounding factor during RHC. All pressure measurements are the difference between the pressure at the chosen zero level and the pressure within the cardiac chamber or vessel where the catheter tip is positioned 5 . A zero-level set five $\mathrm{cm}$ above (or below) the midthoracic level results in underestimation (or overestimation) of all pressures by approximately four $\mathrm{mmHg}$. This may significantly affect management of patients. 
Table 1 Clinical objectives of RHC in PH/PAH.

\begin{tabular}{|c|c|c|}
\hline $\begin{array}{l}\text { Main clinical issues to be } \\
\text { addressed by RHC }\end{array}$ & In the diagnostic phase & During follow-up \\
\hline Is PH present? & $\begin{array}{l}\text { Hemodynamic definition = mean PAP }>\mathbf{2 0} \\
\mathrm{mmHg} \text { and } \mathrm{PVR} \geq 3 \mathrm{WU} .\end{array}$ & \\
\hline Is PH pre or post-capillary? & $\begin{array}{l}\text { Accurate measure of PAWP is crucial } \\
\text { (sometimes LVEDP is required). Fluid } \\
\text { challenge may be useful.Agreement with } \\
\text { pre-test clinical evaluation and imaging data } \\
\text { is necessary. }\end{array}$ & \\
\hline Is PH causing right ventricular failure? & $\begin{array}{l}\mathrm{RAP}>14 \mathrm{mmHg}, \mathrm{Cl}<2.0 \mathrm{l} / \mathrm{min} / \mathrm{m}^{2} \text { and } \mathrm{SvO} 2 \\
<60 \% \text { defines a situation of } \mathrm{RV} \text { failure and } \\
\text { thus characterize the highest risk patients }\end{array}$ & \\
\hline Which is the risk of the patient? & & $\begin{array}{l}\text { Low-risk cutoffs: } \mathrm{RAP}<\mathbf{8} \mathrm{mmHg} ; \mathrm{Cl} \geq \mathbf{2 . 5} \\
\mathrm{l} / \mathrm{min} / \mathrm{m}^{2} ; \mathrm{SvO} 2>65 \% \text { Intermediate- } \\
\text { risk cutoffs: RAP } 8-14 \mathrm{mmHg} ; \mathrm{Cl} 2.0-2.4 \\
\mathrm{l} / \mathrm{min} / \mathrm{m}^{2} ; \mathrm{SvO2} 60-65 \% \mathrm{High}-\text { risk cutoffs: } \\
\mathrm{RAP}>14 \mathrm{mmHg} ; \mathrm{Cl}<2.0 \mathrm{l} / \mathrm{min} / \mathrm{m}^{2} ; \mathrm{SvO2} \\
<60 \%\end{array}$ \\
\hline Is pharmacological treatment effective? & & $\begin{array}{l}\text { Based on assessment of changes not only in } \\
\text { PVR but also in } \mathrm{Cl} \text { (or SVi) and RAP. }\end{array}$ \\
\hline
\end{tabular}

The zero reference defines the location in the circulatory system where changes in body position do not affect pressure measurements. The current consensus is that pressure transducer should be zeroed at the mid-thoracic level (midpoint between anterior sternum and bed surface) with the patient supine, which best approximates the level of the right atrium. These references should be maintained for the entire duration of the procedure.

The thermodilution technique can be considered the preferred method of cardiac output monitoring, even among patients with very low cardiac output and/or severe tricuspid regurgitation. Thermodilution has in fact proven to be a reliable method when compared with the direct Fick measurement; on the contrary, the indirect Fick method is less reliable than the other techniques.

In order to cope with the intrinsic random errors of pressure and flow determinations made with a fluid-filled pulmonary artery catheter, it is now clearly recommended that measurements should be repeated in triplicate to obtain values within a $10 \%$ agreement and averaged ${ }^{6,7}$.

\section{Which are the clinical issues to be addressed by the diagnostic RHC?}

- Is PH present?

- Is PH pre-capillary or post-capillary?

- Does PH cause right ventricular failure?

\section{Is PH present?}

The hemodynamic definition of $\mathrm{PH}$ is based on the value of mean pulmonary arterial pressure (mPAP) which must be $\geq 25 \mathrm{mmHg}$ at rest according to $2015 \mathrm{ESC} /$ ERS Guidelines. This can only be obtained at RHC. Doppler echocardiography is used to estimate the right ventricular (RV) systolic pressure by estimating the pressure gradient between the right ventricle and the right atrium using the modified Bernoulli equation; an estimate of right atrial pressure obtained by the evaluation of dimensions and 
collapsibility of the inferior vena cava must be added to this number to approximate the RV systolic pressure, which coincides with the systolic pulmonary artery pressure (SPAP) in the absence of pulmonic stenosis.

Numerous methods have been suggested to derive non-invasively mPAP by sPAP,9, however, these have not gained clinical acceptance in international guidelines. In general, Doppler echocardiography allows for accurate measurements of the pulmonary circulation, but has only moderate precision, which explains why echocardiographic estimates of pulmonary pressures are valid for population studies, but cannot be used for the individual diagnosis of pulmonary hypertension ${ }^{10}$.

In addition, the relationship between the systolic and the mean pressure in a vessel is not linear but it is highly dependent on the stiffness of the vessels, which may vary from patient to patient and cannot be determined non-invasively.

A new hemodynamic threshold for PH has been proposed by the 6th WSPH Task Force on $\mathrm{PH}$ diagnosis and classification (combination of mPAP $>20 \mathrm{mmHg}$ and pulmonary vascular resistance (PVR) $\geqslant 3$ Wood Units) ${ }^{11}$. Including pulmonary vascular resistance in the definition of pre-capillary PH is essential, allowing discrimination of elevation of PAP due to pulmonary vascular disease from those due to elevation of PAWP due to high cardiac output. This new definition reinforces the necessity of using the RHC for a precise definition of presence/absence of $\mathrm{PH}$.

\section{Is $\mathbf{P H}$ pre-capillary or post-capillary?}

Accurate measurement of left atrial pressure is essential for distinguishing pre-capillary from post-capillary PH, i.e., patients with left heart disease. In particular, heart failure with preserved ejection fraction (HFpEF) is most frequently misclassified as PAH and thus erroneously treated with PAH-specific therapy. Pulmonary artery wedge pressure (PAWP) is commonly used as a surrogate of left atrial pressure; in the absence of mitral stenosis, PAWP measured at end-diastole (i.e., typically as the mean of the a-wave or, alternatively, a QRS-gated approach) more closely approximates left ventricular end-diastolic pressure $\left(\right.$ LVEDP $^{12,13}$. LVEDP direct measurement is only used when an accurate PAWP cannot be obtained $^{14}$.

PAWP is obtained using a Swan-Ganz catheter with the balloon inflated in a branch pulmonary artery, preventing blood flow or the transmission of pressure from the proximal pulmonary arteries. The static column of blood transmits left atrial pressure to the catheter tip, allowing an estimate of left atrial pressure. Obtaining a reliable PAWP requires expertise and attention. It is important to achieve a stable balloon occlusion position, avoiding under-wedging or over-wedging.

Pressure measurements are to be carefully recorded at end expiration, ensuring that the patient does not produce a Valsalva manoeuvre. All pressure values, including PAWP, are recorded as the mean of 3 to 5 measurements obtained at the end of normal expiration. This guideline recommendation may not be applicable in patients with chronic obstructive pulmonary disease (COPD), in whom there is often a prominent swing in intrathoracic pressure affecting intracardiac pressures. Averaging PAWP over several respiratory cycles may be the most reasonable compromise to compensate for respiratory fluctuations as positive expiratory and negative inspiratory intrathoracic pressures cancel each other out ${ }^{6}$.

There are several tricks to be sure that an accurate PAWP is obtained, including: PAWP value should be equal to or lower than diastolic pulmonary arterial pressure, the PAWP waveform must exhibit clear $A$ and $V$ waves, a respiratory swing should be visible, blood 
sampling from the distal lumen of the catheter should detect an oxygen saturation in the occlusion position similar or higher than the systemic saturations.

However, expert clinicians must be aware of the fact that the optimal PAWP threshold for distinguishing pre-capillary from post-capillary PH remains a matter of debate. Although the $2015 \mathrm{ESC} / \mathrm{ERS}$ guidelines recommend a threshold of $15 \mathrm{mmHg}$, values between 10 and $18 \mathrm{mmHg}$ have also been suggested ${ }^{15-19}$. The first randomized, multicenter trial comparing the effects of the continuous intravenous infusion of epoprostenol plus conventional therapy vs, conventional therapy alone in patients with severe primary pulmonary hypertension included patients with PAWP $\leq 12 \mathrm{mmHg}^{16}$.

In the REVEAL registry, a cutoff of $18 \mathrm{mmHg}$ was used to avoid misclassifying older patients with PAH or patients with pulmonary vascular disease and a minor degree of left ventricular diastolic dysfunction ${ }^{19}$. In general, high cutoff risks misclassifying HFpEF patients as PAH, whereas a lower threshold carries the opposite risk. Therefore, most importantly, the hemodynamic values recorded at the diagnostic RHC must be in accordance with the clinical picture and with the non-invasive information ${ }^{20}$. This means that a complete and accurate diagnostic RHC is always preceded by a clinical evaluation of the patient and by a focused echocardiographic and Doppler examination to have a pre-test probability of PH due to left heart disease. The clinician performing the diagnostic RHC must correctly interpret the hemodynamic values recorded during the catheterization.

Importantly, PAWP is not a constant value, but a dynamic parameter affected by the afterload of the left ventricle and by fluid balance. In many patients with left heart disease, PAWP can be lowered to less than $15 \mathrm{mmHg}$ with intense diuretic treatment and vasodilator administration. Therefore, if the a priori probability of post-capillary PH is high (due to the presence of risk factors or to the presence of an enlarged left atrium and of diastolic dysfunction at echocardiography) and a low PAWP is recorded, RHC must include a fluid challenge test to uncover latent HFpEF ${ }^{21}$.

In the opposite situation, i.e., a high pre-test probability of pre-capillary $\mathrm{PH}$ and recorded PAWP values above $15 \mathrm{mmHg}$, the clinician should be prompted to re-check the zero level and to wedge the catheter in different positions.

In case of post-capillary $\mathrm{PH}$, this should be classified as: 1) isolated $\mathrm{PH}(\mathrm{IPCPH})$ : PAWP $>15 \mathrm{mmHg}$ and $\mathrm{mPAP}>20 \mathrm{mmHg}$ and PVR $<3 \mathrm{WU}$; or 2) combined PH (CPcPH): PAWP $>15 \mathrm{mmHg}$ and $\mathrm{mPAP}>20 \mathrm{mmHg}$ and $\mathrm{PVR} \geqslant 3 \mathrm{WU}^{12}$.

Finally, in patients with idiopathic, heritable or drug-related PAH, the diagnostic RHC must include an acute pulmonary vasoreactivity test in order to identify patients suitable for calcium channel blocker therapy. Vasoreactivity testing is usually performed with inhaled nitric oxide (10 to 20 parts per million). A positive test is defined as a reduction of $\mathrm{mPAP} \geq 10 \mathrm{mmHg}$ from baseline to an absolute value of $\mathrm{mPAP} \leq 40 \mathrm{mmHg}$ with unchanged or increased cardiac output ${ }^{1}$.

\section{Is PH causing right ventricular failure?}

In the 1980s, the National Institutes of Health (NIH) Registry on Primary Pulmonary Hypertension demonstrated that mortality in incident PAH patients best correlates with two hemodynamic variables obtained at the diagnostic RHC which describe RV function: i.e., one indicator of pump function (cardiac index, $\mathrm{Cl}$ ) and one indicator of systemic congestion (right atrial pressure, RAP) ${ }^{16}$.

The latest recommended treatment algorithm for incident PAH patients foresees choice between two options. Patients at low or intermediate risk should be treated with 
initial oral combination therapy with an ERA and a PDE5i (monotherapy is limited to specific PAH subsets).

In high-risk patients, combination therapy including i.v. prostacyclin analogues is recommended.

Although risk assessment in PAH is complex and must be based on a multidimensional evaluation of the patients, what is necessary in incident patients is only to identify the highest risk subgroup. This is easy using the hemodynamic parameters obtained at RHC: RAP $>14 \mathrm{mmHg}, \mathrm{Cl}<2.0 \mathrm{l} / \mathrm{min} / \mathrm{m}^{2}$ and $\mathrm{SvO}_{2}<60 \%$ defines a situation of RV failure and thus characterize the highest risk patients.

\section{Which clinical issues are to be addressed by RHC during the follow-up of PAH patients?}

- What is the risk of the patient?

- Is pharmacological treatment effective?

\section{Risk stratification}

The assessment of the prognosis has always been considered an important part of the evaluation of PAH patients since the publication of the NIH registry nearly three decades ago, demonstrating the strong association with mortality of a low $\mathrm{Cl}$ and of an elevated $\mathrm{RAP}^{16}$. Over time, different tools have been proposed to predict outcome, but these two hemodynamic variables maintained a pivotal role in the assessment of prognosis in $\mathrm{PAH}^{22-26}$.

The 2015 ESC/ERS PH guidelines introduced the recommendation of regular and comprehensive risk assessment at expert centers using a range of invasive and noninvasive parameters; the guidelines in fact stated that the goal of treatment in patients with pulmonary arterial hypertension $(\mathrm{PAH})$ is to achieve or maintain a low-risk clinical profile.

The complexity of the 2015 ESC/ERS chart for risk assessment was overcome in 2017, when novel abbreviated versions of the ESC/ERS risk stratification model were evaluated retrospectively in newly diagnosed cohorts of PAH patients demonstrating that it is possible to stratify patients into low, intermediate and high risk of events ${ }^{27-29}$.

As expected, hemodynamic parameters play a relevant role in these tools. Importantly, haemodynamic parameters at the time of follow-up RHC are also independently associated with better long-term outcome. In particular, there is additional value in quantifying the stroke volume index (SVi) from a follow-up RHC; patients with a $\mathrm{SVi}<38 \mathrm{ml} \cdot \mathrm{m}^{2}$ have worse long-term outcomes even when multiple low-risk criteria are present ${ }^{30,31}$.

An intense debate is ongoing in the literature on the role of non-invasive markers of prognosis and whether these could eventually replace the invasive hemodynamic assessment ${ }^{32,33}$. In the study from the French registry, brain natriuretic peptide (BNP) or $\mathrm{N}$-terminal (NT)-pro-BNP measurements, NYHA functional class evaluation and exercise capacity at 6MWD allowed to identify a subgroup at low-risk, having a 100\%, 99\% and $97 \%$ survival at 2, 3 and 5 years, respectively.

The usefulness of non-invasive methods to identify low-risk groups was confirmed in the COMPERA registry, with 1-, 3-, and 5-year survival rates of $100 \%, 100 \%$ and $95 \%$, respectively 34 . However, a main issue is that only a small minority of patients meets all these noninvasive criteria during follow-up ( $9 \%$ in the COMPERA study and $19 \%$ in the French study). Thus, most patients (who are classified in an intermediate risk condition) should perform RHC to better elucidate pulmonary haemodynamics and right ventricular function, thus clarifying their risk. 
One could argue that non-invasive imaging techniques, either magnetic resonance imaging (MRI) or echocardiography, being able to provide a direct evaluation of the right heart structure and function, should be superior to any indirect evaluation of the right ventricular function provided by hemodynamic parameters. As a matter of fact, the prognosis of PAH patients is determined by the impact of the elevated afterload on the function of the right ventricle ${ }^{35-37}$.

There is no doubt in the literature that assessment of right ventricular function with MRI is of great prognostic utility in $\mathrm{PAH}^{38-40}$. The usefulness of echocardiography is more controversial, possibly because it is considered a less robust technique than MRI, despite the extensive literature reporting that a great number of echocardiographic variables may provide significant prognostic information ${ }^{41-46}$. Currently, the only echocardiographic parameters included in the risk assessment chart of the ESC/ERS 2015 guidelines are pericardial effusion and right atrial area. In summary, the weight of the evidence available at the current time favours the utility of RHC for routine follow-up of PAH patients.

We believe that in the future routine RHC may not be necessary during follow-up for specific subgroups of patients, possibly those who meet noninvasive low-risk criteria, but this has yet to be demonstrated.

\section{Evaluation of drug efficacy}

The issue of evaluation of drug efficacy is strictly linked with the issue of risk stratification. Treatment of PAH patients cannot be considered as a simple prescription of drugs, but it is a complex strategy that includes an initial multidimensional evaluation of severity of the disease and the subsequent response to treatment; thus, RHC is an important part in the evaluation of response. In fact, the goal of treatment in patients with PAH is achieving a low-risk status, which, hemodynamically, is characterized by a $\mathrm{RAP}<8 \mathrm{mmHg}$ and $\mathrm{a} \mathrm{Cl} \geq 2.5 \mathrm{l} / \mathrm{min} / \mathrm{m}^{2}$.

Not unexpectedly, RHC has been used to test drug efficacy in the seminal randomized, controlled trials for currently approved PAH therapies. In these trials the hemodynamic parameters used as end points (not necessarily primary end-points) were PVR, $\mathrm{Cl}$ and RAP. Other additional hemodynamic parameters describing RV function have been occasionally used to define drug efficacy, such as RV stroke work, RV power or pulmonary arterial compliance but none has so far been validated.

\section{CONCLUSIONS}

In PAH patients, RHC is mandatory to establish the presence and the hemodynamic type of $\mathrm{PH}$. It is also extremely important during the follow-up of $\mathrm{PAH}$ patients to evaluate the risk of the patients, to guide therapy and to assess efficacy of treatments.

Performing a correct and complete RHC in PAH requires not only knowledge and expertise in the procedure itself but, additionally, knowledge and expertise in the different clinical issues to be addressed in the different clinical situations in which RHC is necessary.

\section{REFERENCES}

[1] Galiè N, Humbert M, Vachiery JL, Gibbs S, Lang I, Torbicki A, Simonneau G, Peacock A, Vonk Noordegraaf A, Beghetti M, Ghofrani A, Gomez Sanchez MA, Hansmann G, Klepetko W, Lancellotti P, Matucci M, McDonagh T, Pierard LA, Trindade PT, Zompatori M, Hoeper M. ESC/ERS Guidelines for the diagnosis and treatment of pulmonary hypertension. The Joint Task Force for the Diagnosis and Treatment of Pulmonary Hypertension of the European Society of Cardiology (ESC) and the European Respiratory Society (ERS). Eur Respir J. 2015;46:903-975. 
[2] D’Alto M, Dimopoulos K, Coghlan JG, Kovacs G, Rosenkranz S, Naeije R. Right heart catheterization for the diagnosis of pulmonary hypertension: Controversies and practical issues. Heart Fail Clin. 2018;14:467-477.

[3] McGee DC, Gould MK. Preventing complications of central venous catheterization. N Engl J Med. 2003;348:1123-1133.

[4] Troianos CA, Hartman GS, Glas KE, Skubas NJ, Eberhardt RT, Walker JD, Reeves ST. Councils on intraoperative echocardiography and vascular ultrasound of the American Society of Echocardiography; Society of Cardiovascular Anesthesiologists. J Am Soc Echocardiogr. 2011;24:1291-1318.

[5] McGee SR. Physical examination of venous pressure: a critical review. Am Heart J. 1998;136:10-18.

[6] Kovacs G, Avian A, Pienn M, Naeije R, Olschewski H. Reading pulmonary vascular pressure tracings. How to handle the problems of zero leveling and respiratory swings. Am J Respir Crit Care Med. 2014;3:252-257.

[7] Naeije R, D’Alto M, Forfia PR. Clinical and research measurement techniques of the pulmonary circulation: the present and the future. Prog Cardiovasc Dis. 2015;5:463-472.

[8] Chemla D, Castelain V, Humbert M, Hébert JL, Simonneau G, Lecarpentier Y, Hervé P. New formula for predicting mean pulmonary artery pressure using systolic pulmonary artery pressure. Chest. 2004;126:1313-1317.

[9] Chemla D, Castelain V, Provencher S, Humbert M, Simonneau G, Hervé P. Evaluation of various empirical formulas for estimating mean pulmonary artery pressure by using systolic pulmonary artery pressure in adults. Chest. 2009;135:760-768.

[10] D’Alto M, Romeo E, Argiento P, D’Andrea A, Vanderpool R, Correra A, Bossone E, Sarubbi B, Calabrò R, Russo MG, Naeije R. Accuracy and precision of echocardiography versus right heart catheterization for the assessment of pulmonary hypertension. Int J Cardiol. 2013;168:4058-4062.

[11] Simonneau G, Montani D, Celermajer DS, Denton CP, Gatzoulis MA, Krowka M, Williams PG, Souza R. Haemodynamic definitions and updated clinical classification of pulmonary hypertension. Eur Respir J. 2019;53(1).

[12] Vachiéry JL, Tedford RJ, Rosenkranz S, Palazzini M, Lang I, Guazzi M, Coghlan G, Chazova I, DeMarco T. Pulmonary hypertension due to left heart disease. Eur Respir J. 2019;53(1).

[13] Houston BA, Tedford RJ. What we talk about when we talk about the wedge pressure. Circ Heart Fail. 2017;10(9).

[14] Rosenkranz S, Gibbs JS, Wachter R, De Marco T, Vonk-Noordegraaf A, Vachiéry J-L. Left ventricular heart failure and pulmonary hypertension. Eur Heart J. 2016;37:942-954.

[15] Stevens PM. Assessment of acute respiratory failure: cardiac versus pulmonary causes. Chest. 1975;67:1-2.

[16] D’Alonzo GE, Barst RJ, Ayres SM, Bergofsky EH, Brundage BH, Detre KM, Fishman AP, Goldring RM, Groves BM, Kernis JT, et al. Survival in patients with primary pulmonary hypertension. Results from a national prospective registry. Ann Intern Med. 1991;115:343-349.

[17] Barst RJ, Rubin LJ, Long WA, McGoon MD, Rich S, Badesch DB, Groves BM, Tapson VF, Bourge RC, Brundage BH, Koerner SK, Langleben D, Keller CA, Murali S, Uretsky BF, Clayton LM, Jöbsis MM, Blackburn SD, Shortino D, Crow JW, Primary Pulmonary Hypertension Study Group. A comparison of continuous intravenous epoprostenol (prostacyclin) with conventional therapy for primary pulmonary hypertension. N Engl J Med. 1996;334:296-301.

[18] Paulus WJ, Tschöpe C, Sanderson JE, Rusconi C, Flachskampf FA, Rademakers FE, Marino P, Smiseth OA, De Keulenaer G, Leite-Moreira AF, Borbély A, Edes I, Handoko ML, Heymans S, Pezzali N, Pieske B, Dickstein K, Fraser AG, Brutsaert DL. How to diagnose diastolic heart failure: a consensus statement on the diagnosis of heart failure with normal left ventricular ejection fraction by the Heart Failure and Echocardiography Associations of the European Society of Cardiology. Eur Heart J. 2007;28:2539-2550.

[19] McGoon MD, Krichman A, Farber HW, Barst RJ, Raskob GE, Liou TG, Miller DP, Feldkircher K, Giles S. Design of the REVEAL registry for US patients with pulmonary arterial hypertension. Mayo Clin Proc. 2008;83:923-931.

[20] Gerges C, Gerges M, Skoro-Sajer N, Zhou Y, Zhang L, Sadushi-Kolici R, Jakowitsch J, Lang MB, Lang IM. Hemodynamic thresholds for precapillary pulmonary hypertension. Chest. 2016;149(4):1061-1073.

[21] D’Alto M, Romeo E, Argiento P, Motoji Y, Correra A, Di Marco GM, lacono AM, Barracano R, D’Andrea A, Rea G, Sarubbi B, Russo MG, Naeije R. Clinical relevance of fluid challenge in patients evaluated for pulmonary hypertension. Chest. 2017;151:119-126.

[22] McLaughlin VV, Shillington A, Rich S. Survival in primary hypertension - The impact of Epoprostenol therapy. Circulation. 2002;106:1477-1482.

[23] Sitbon O, Humbert M, Nunes H, Parent F, Garcia G, Herve P, Rainisio M, Simonneau G. Long-term intravenous epoprostenol infusion in primary pulmonary hypertension: prognostic factors and survival. J Am Coll Cardiol. 2002;40:780-788.

[24] Campo A, Mathai SC, Le Pavec J, Zaiman AL, Hummers LK, Boyce D, Housten T, Champion HC, Lechtzin N, Wigley FM, Girgis RE, Hassoun PM. Hemodynamic predictors of survival in scleroderma-related pulmonary arterial hypertension. Am J Respir Crit Care Med. 2010;182:252-260.

[25] Nickel N, Golpon H, Greer M, Knudsen L, Olsson K, Westerkamp V, Welte T, Hoeper MM. The prognostic impact of follow-up assessments in patients with idiopathic pulmonary arterial hypertension. Eur Respir J. 2012;39:589-596.

[26] Galiè N, Jansa P, Pulido T, Channick RN, Delcroix M, Ghofrani HA, LeBrun FO, Mehta S, Perchenet L, Rubin LJ, Sastry BKS, Simonneau G, Sitbon O, Souza R, Torbicki A. SERAPHIN haemodynamic substudy: 
the effect of the dual endothelin receptor antagonist macitentan on haemodynamic parameters and NT-proBNP levels and their association with disease progression in patients with pulmonary arterial hypertension. Eur Heart J. 2017;38:1147-1155.

[27] Kylhammar D, Kjellström B, Hjalmarsson C, Jansson K, Nisell M, Söderberg S, Wikström G, Rådegran $\mathrm{G}$. A comprehensive risk stratification at early follow-up determines prognosis in pulmonary arterial hypertension. Eur Heart J. 2018;39:4175-4181.

[28] Boucly A, Weatherald J, Savale L, Jaïs X, Cottin V, Prevot G, Picard F, deGroote P, Jevnikar M, Bergot E, Chaouat A, Chabanne C, Bourdin A, Parent F, Montani D, Simonneau G, Humbert M, Sitbon O. Risk assessment, prognosis and guideline implementation in pulmonary arterial hypertension. Eur Respir J. 2017;50(2).

[29] Hoeper MM, Kramer T, Pan Z, Eichstaedt CA, Spiesshoefer J, Benjamin N, Olsson KM, Meyer K, Vizza CD, Vonk-Noordegraaf A, Distler O, Opitz C, Gibbs JSR, Delcroix M, Ghofrani HA, Huscher D, Pittrow D, Rosenkranz S, Grünig E. Mortality in pulmonary arterial hypertension: prediction by the 2015 European pulmonary hypertension guidelines risk stratification model. Eur Respir J. 2017;50(2).

[30] Weatherald J, Boucly A, Chemla D, Savale L, Peng M, Jevnikar M, Jaïs X, Taniguchi Y, O'Connell C, Parent F, Sattler C, Hervé P, Simonneau G, Montani D, Humbert M, Adir Y, Sitbon O. Prognostic value of followup hemodynamic variables after initial management in pulmonary arterial hypertension. Circulation. 2018;137:693-704.

[31] Rubin LJ. Assessing prognosis of pulmonary arterial hypertension in the therapeutic era: importance of serial hemodynamic measurements. Circulation. 2018;137:705-706.

[32] Humbert M, Weatherald J. Right heart catheterisation is still a fundamental part of the follow-up assessment of pulmonary arterial hypertension. Eur Respir J. 2018;52(1).

[33] Howard LS. Is right heart catheterisation still a fundamental part of the follow-up assessment of pulmonary arterial hypertension? The argument against. Eur Respir J. 2018;52(1).

[34] Hoeper MM, Pittrow D, Opitz C, Gibbs JSR, Rosenkranz S, Grünig E, Olsson KM, Huscher D. Risk assessment in pulmonary arterial hypertension. Eur Respir J. 2018;51: 1702606.

[35] van de Veerdonk MC, Kind T, Marcus JT, Mauritz GJ, Heymans MW, Bogaard HJ, Boonstra A, Marques KM, Westerhof N, Vonk-Noordegraaf A. Progressive right ventricular dysfunction in patients with pulmonary arterial hypertension responding to therapy. J Am Coll Cardiol. 2011;58:2511-2519.

[36] Courand PY, Pina Jomir G, Khouatra C, Scheiber C, Turquier S, Glérant JC, Mastroianni B, Gentil B, Blanchet-Legens AS, Dib A, Derumeaux G, Humbert M, Mornex JF, Cordier JF, Cottin V. Prognostic value of right ventricular ejection fraction in pulmonary arterial hypertension. Eur Respir J. 2015;45(1):139-149.

[37] Ghio S, Pica S, Klersy C, Guzzafame E, Scelsi L, Raineri C, Turco A, Schirinzi S, Visconti LO. Prognostic value of TAPSE after therapy optimisation in patients with pulmonary arterial hypertension is independent of the haemodynamic effects of therapy. Open Heart. 2016;3(1):e000408.

[38] van Wolferen SA, Marcus JT, Boonstra A, Marques KM, Bronzwaer JG, Spreeuwenberg MD, Postmus PE, Vonk-Noordegraaf A. Prognostic value of right ventricular mass, volume, and function in idiopathic pulmonary arterial hypertension. Eur Heart J. 2007;28:1250-1257.

[39] Swift AJ, Capener D, Johns C, Hamilton N, Rothman A, Elliot C, Condliffe R, Charalampopoulos A, Rajaram S, Lawrie A, Campbell MJ, Wild JM, Kiely DG. Magnetic resonance imaging in the prognostic evaluation of patients with pulmonary arterial hypertension. Am J Respir Crit Care Med. 2017;196:228-239.

[40] Trip P, Kind T, van de Veerdonk MC, Marcus JT, de Man FS, Westerhof N, Vonk-Noordegraaf A. Accurate assessment of load-independent right ventricular systolic function in patients with pulmonary hypertension. J Heart Lung Transplant. 2013;32:50-55.

[41] Forfia PR, Fisher MR, Mathai SC, Housten-Harris T, Hemnes AR, Borlaug BA, Chamera E, Corretti MC, Champion HC, Abraham TP, Girgis RE, Hassoun PM. Tricuspid annular displacement predicts survival in pulmonary hypertension. Am J Respir Crit Care Med. 2006;174:1034-1041.

[42] Ghio S, Klersy C, Magrini G, D’Armini AM, Scelsi L, Raineri C, Pasotti M, Serio A, Campana C, Viganò M. Prognostic relevance of the echocardiographic assessment of right ventricular function in patients with idiopathic pulmonary arterial hypertension. Int J Cardiol. 2010;140:272-278.

[43] Mukherjee M, Mercurio V, Tedford RJ, Shah AA, Hsu S, Mullin CJ, Sato T, Damico R, Kolb TM, Mathai SC, Hassoun PM. Right ventricular longitudinal strain is diminished in systemic sclerosis compared with idiopathic pulmonary arterial hypertension. Eur Respir J. 2017;50(5).

[44] Tello K, Axmann J, Ghofrani HA, Naeije R, Narcin N, Rieth A, Seeger W, Gall H, Richter MJ. Relevance of the TAPSE/PASP ratio in pulmonary arterial hypertension. Int J Cardiol. 2018;266:229-235.

[45] Dandel M. Echocardiographic variables with prognostic value in pulmonary arterial hypertension. Int J Cardiol. 2019;294:59.

[46] Ghio S, Mercurio V, Fortuni F, Forfia PR, Gall H, Ghofrani A, Mathai SC, Mazurek JA, Mukherjee M, Richter M, Scelsi L, Hassoun PM, Tello K, TAPSE in PAH investigators (full list in appendix). A comprehensive echocardiographic method for risk stratification in pulmonary arterial hypertension. Eur Respir J. 2020;2000513. 